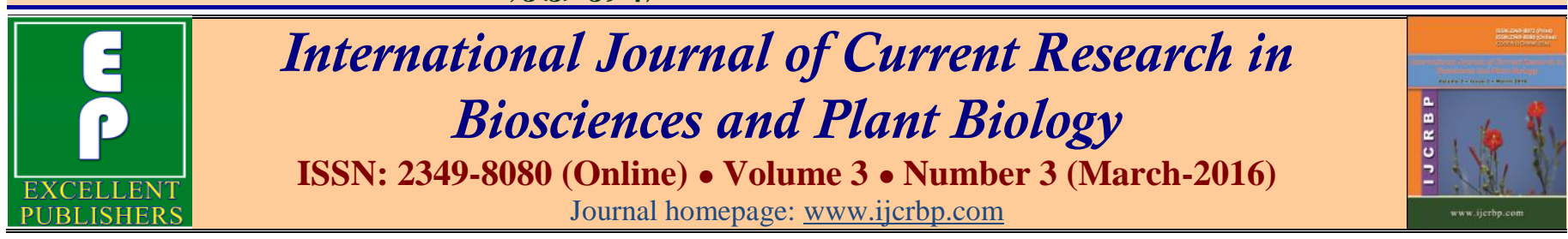

\title{
Physicochemical Characteristics and Suitability for Selected Local Foods of the Elite Cassava (Manihot esculenta Crantz) Cultivars of Central Benin
}

\author{
D. R. Gbessovi ${ }^{1}$, P. Agre ${ }^{1}$, A. F. Sanoussi ${ }^{1}$, A. Dassou ${ }^{1}$, A. Dansi ${ }^{*}$, A. Adjatin ${ }^{2}$, M. Dansi ${ }^{1}$ and $^{2}$ \\ H. Ahissou ${ }^{3}$
}

${ }^{1}$ Laboratory of Biotechnology, Genetic Resources and Plant and Animal Breeding (BIORAVE), Faculty of Sciences and Technology of Dassa, Polytechnic University of Abomey, BP 14 Dassa, Benin

${ }^{2}$ Faculty of Sciences and Technology of Dassa, Polytechnic University of Abomey, BP 14 Dassa, Benin

${ }^{3}$ Laboratory of Protein Biochemistry and Enzymology, Faculty of Sciences and Technology (FAST), University of Abomey-Calavi (UAC), PO Box 526 Cotonou, Benin

*Corresponding author.

\begin{abstract}
In Benin Republic, Cassava (Manihot esculenta Crantz) is one of the highly produced and consumed food crops. In this 34 cassava elite cultivars of Central Benin were assessed for dry matter content, starch content, cyanide content and alcohol production capacity using appropriate methodologies. Dry matter content varies from $35.36 \%$ to 50 . $80 \%$ with (average of $35.98 \%$ ) and 19 elite cultivars presented high values superior to the average. Starch content varies from $0.14 \mathrm{mg} / \mathrm{g}$ to $11.14 \mathrm{mg} / \mathrm{g}$ with 8 cultivars having high values. Value of $0.13 \mathrm{ml} / \mathrm{g}$ as average was obtained for the alcohol production capacity and 4 cassava cultivars suitable for this purpose were identified. Positive correlation $(\mathrm{R}=0.48)$ was found between starch content and alcohol production capacity. The suitability of each cultivar to be processed into gari, chips (dry peeled root), tapioca (dry starch), cassava flour and Attièkè was evaluated through sensorial analysis. Principal component analysis and dendrogram were performed to classify cultivars into four different groups based on their physicochemical characteristics. Cultivars that presented high values for the different parameters considered were recommended to cassava processors for various cassava foods.
\end{abstract}

\section{Introduction}

In tropical regions, Cassava (Manihot esculenta Crantz) plays an important role in food security and poverty alleviation (Parkes et al., 2013). Cassava is rich in carbohydrates and sustainably contributes to nourish millions of people because of its availability over the year (Hongbété et al., 2011; Sanoussi et al., 2015). In West Africa, cassava roots, are processed into many products and consumed in various ways. Cassava leaves are rich in proteins and are consumed as leafy vegetable

\section{Article Info}

Accepted: 02 March 2016

Available Online: 06 March 2016

Keywords

Cassava

Cassava foods

Elite cultivar

Manihot esculenta

Physicochemical analysis
(Essuma et al., 2012). In Benin, cassava is grown across all agroecological zones and, in terms of production, ranks second after maize (Agre et al., 2015a). It is consumed either raw or most frequently after processing into many cassava based products such as gari, attièkè, chips, starch and cassava flour (Nago et al., 1998; Sanoussi et al., 2015). Among the different products listed, gari is the most important and is produced by more than $70 \%$ of cassava processors (Nago et al., 1998). Tapioca, the dehydrated cassava starch partially gelatinized and roasted is lesser produced than 
gari but largely known and consumed locally (Sanoussi et al., 2015). High Quality Cassava Flour production (HQCF) was experienced, it level of adoption through the country evaluated (Rahmi et al., 2008) and its utilization for breads and biscuits reported (Falade and Akingbala, 2008; Onubuogu et al., 2014). The ethylic alcohol obtained through fermentation process of the cassava starch is documented in Benin and a local alcohol processing unit exists at Logozohè in Central Benin. However, there is lack of information on the physicochemical composition of the local cassava cultivars and their technological aptitude. Knowledge of the physicochemical characteristics of a crop can help in orienting processors for better choice of cultivars to be used for different types of products (Sanoussi et al., 2016).

Considering the economic importance of cassava for local farmers, processors and food entrepreneurs, a better knowledge of the local cultivars would help in choice of right cultivars to be used for good quality of end products with a better profit margin. Therefore, it appears necessary to determine based on physicochemical characteristics the best cassava cultivars to be recommended for processors and factories specialized in cassava processing. Hence, the objectives of this study were two-fold:

- Assess some physicochemical characteristics of the elite cassava cultivars of central Benin.

- Classify the cultivars into groups suitable for production of gari, tapioca, chips, attièkè, cassava flour and ethanol with good profit margin based on their physicochemical characteristics.

\section{Materials and methods}

\section{Plant material and preparation of samples for analysis}

Thirty four (34) elite cassava cultivars (Table 1) from Central Benin maintained as field collection at the experimental farm of the Faculty of Sciences and Technology of Dassa (FAST/Dassa) were considered for the physicochemical analysis. The elite cultivars are those produced by many households on large area (Agre et al., 2015b). Among the 34 cultivars selected, 8 (Table 1) were of bitter taste with a probably high hydrocyanic acid content (Agre et al., 2015b). These cultivars were analyzed for their level of toxicity via their real cyanide content. For each cultivars to be analyzed, fresh root flesh was collected, ground by Moulinex DPA1 41 and the obtained paste homogenized and stored in a refrigerator $\left(10^{\circ} \mathrm{C}\right)$ for future analysis of dry matter and starch content as well as cyanide content.

\section{Physicochemical analysis}

Dry matter was determined following the standard method of AOAC (AOAC, 2000) by drying $5 \mathrm{~g}$ of cassava mash in the oven at the temperature of $105 \circ \mathrm{C}$ until stable products weight was obtained following Sanoussi et al. (2015).

Starch content was evaluated using spectrophotometry method which involves peeling, cutting, grating and cold drying at $10^{\circ} \mathrm{C}$ of cassava samples. The samples were then finely ground and sieved in $0.5 \mathrm{~nm}$ diameter sieve. 5 $\mathrm{g}$ of the sieved mash are introduced into a test tube to which was added $5 \mathrm{ml}$ of potassium hydroxide $\mathrm{KOH} 1 \mathrm{M}$ followed by $5 \mathrm{ml}$ of chlorhydric acid $(\mathrm{HCl}) 1 \mathrm{M}$. The mixture obtained was homogenized using vortex and the $\mathrm{pH}$ of the resulting mixture neutralized. The neutral mixture obtained was boiled at $100^{\circ} \mathrm{C}$ for $5 \mathrm{~min}$, and the volume adjusted to $10 \mathrm{~mL}$ by addition of distilled water. An aliquot of this solution was centrifuged at $3000 \mathrm{rpm}$ for $10 \mathrm{~min}$ to obtain a filtrate. The supernatant volume (Vs) was then measured and $1 \mathrm{ml}$ is removed and diluted to $10 \mathrm{ml}$ with distilled water. The absorbance of subsequent dilution of each sample is read on spectrophotometer set at $580 \mathrm{~nm}$. The starch content was calculated as followed (Sanoussi et al., 2016):

$\mathrm{C}=\mathrm{Vs} \times((\Delta \mathrm{DO}$ Sample -0.016$)) \times 2 / 1.808$

Where,

$\mathrm{C}$ : weight of starch per gram of sample in $\mathrm{mg}$;

Vs: volume of supernatant

White $\triangle \mathrm{DO}: 0.016$

Dilution factor: 2

$\Delta$ DO sample: Optical density of the sample

To determine the alcohol production capacity, a sample of $5 \mathrm{~g}$ of cassava flour was collected and $25 \mathrm{~mL}$ of mixture of $\mathrm{KCl}(1 \mathrm{~g} / \mathrm{L})$ and $\mathrm{MgSO}_{4}(0.5 \mathrm{~g} / \mathrm{L})$ diluted distilled water was added as well as $5 \mathrm{~mL}$ of concentrate sulfuric acid $\left(\mathrm{H}_{2} \mathrm{SO}_{4}\right)$. The resulting mixture was heated to boiling and then cooled down after been neutralized with $\mathrm{NaOH}$ to $\mathrm{pH}$ 3.7. Then $4.5 \mathrm{~g}$ of yeast (Saccharomyces cerevisiae) was added to the mixture obtained for each sample for fermentation at room temperature for $72 \mathrm{hrs}$. The tubes containing the sample mixture are closed with cotton. After the fermentation, the mixture was centrifuged for 10 minutes and the alcohol content determined using alcoholmeter. 
Table 1. Elite cassava cultivars of central Benin.

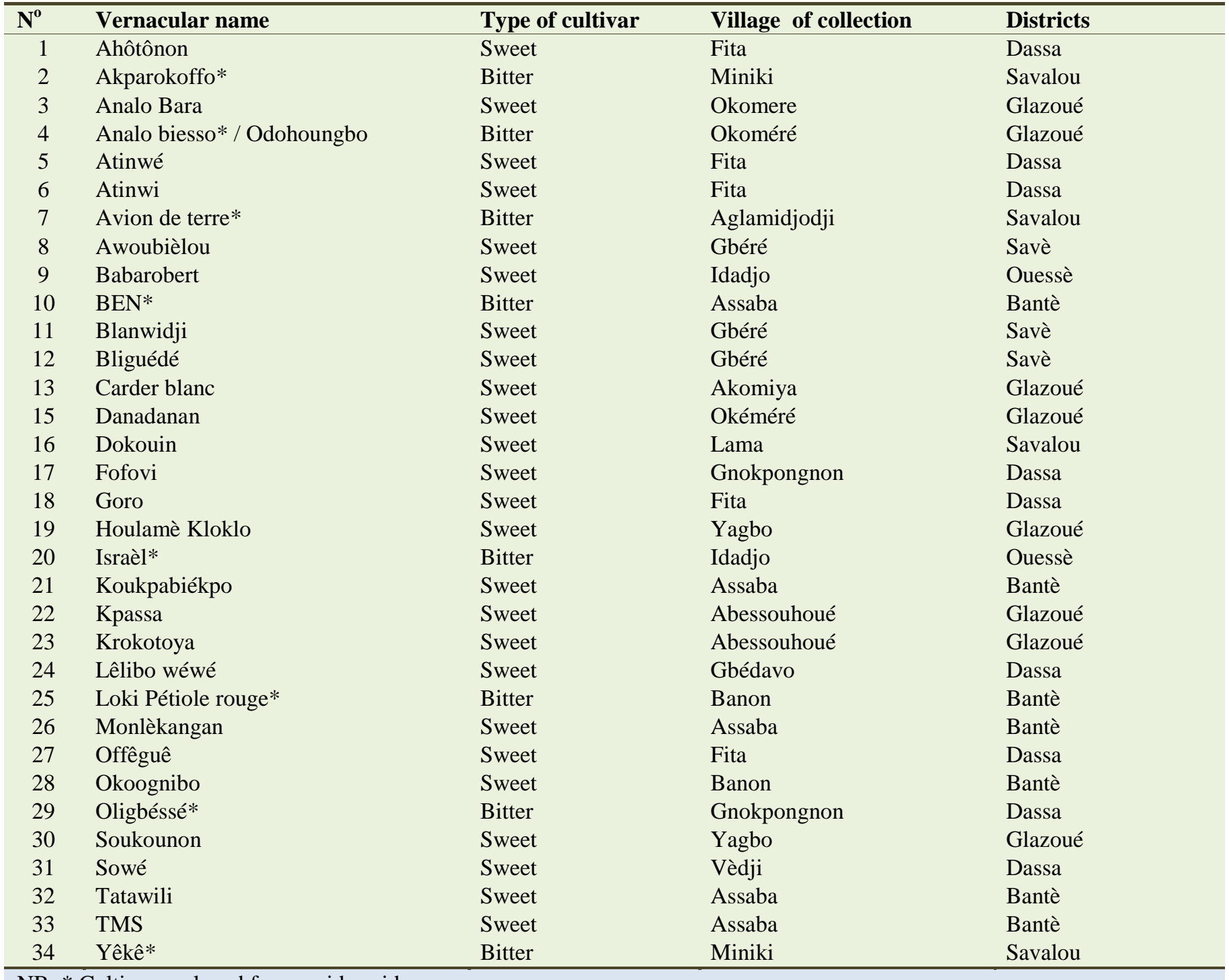

NB: * Cultivar analyzed for cyanide acid.

The cyanide presence in the cultivars was revealed using picric acid text method described as follow (Mehouenou et al., 2016). This method involves the use of Whatman paper soaked in picric acid (as developer) then oven dried and later soaked in Calcium Carbonate $\left(\mathrm{CaCO}_{3}\right)$ (as fixer) and again oven dried. Then $3 \mathrm{~g}$ of cassava flour sample and $10 \mathrm{~mL}$ of distilled water for each sample was taken and inserted into jars obtained for this purpose. The Whatman paper previously prepared was attached to the lid of the jars and everything was sealed to observe evaporation of cyanhydric acid.

\section{Statistical analysis}

The data were analyzed using descriptive statistic (frequencies, percentages, average) and the results presented in the form of Tables and Figures. To identify among the different elite cassava cultivars those that are better adapted for good quality gari, tapioca, cassava chips, alcohol production and flour (HQCF) production, cultivars were considered as individuals and the different physicochemical parameters assessed as variables and coded 1 when applicable and 0 when not. By using this methodology, a binary matrix of 34 individuals and 5 variables was constructed and used to generate a similarity matrix using simple matching coefficient of similarity. This matrix of similarity was used to construct a dendrogram and to perform a Principal Component Analysis (PCA) to group the cultivars analyzed. All the analyses were done using SPAD 5.5 software (Chavent et al., 2007). 


\section{Results and discussion}

\section{Determination of physicochemical characteristics}

A high variation was observed between the different elite cassava cultivars regarding their physicochemical properties (Table 2) especially dry matter content, starch content and alcohol production.

The dry matter content varies from $35.36 \%$ to $50.8 \%$ with an average of $35.98 \%$ (Table 2). The highest value was recorded with cultivar Sowé while the lowest value was obtained with cultivar Offèguè. Nineteen (19) cassava cultivars among the 34 analyzed were found to have high dry matter content (value superior to the average) and can be recommended to processors for utilization through cassava chips and flours following Fiagan (2007), Hongbètè et al. (2011) and Sanoussi et al. (2015). Singh et al. (2007) reported the existence of a high correlation between dry matter content and the aptitude of a cultivar to produce high quantity of gari with good quality. On that basis, the 19 cultivars identified were also recommended for use in processing of cassava into gari in Central Benin.

Table 2. Dry matter, starch content and alcohol production capacity of the cultivars analyzed.

\begin{tabular}{|c|c|c|c|c|}
\hline $\mathbf{N}^{\circ}$ & Cassava cultivars & $\begin{array}{l}\text { Dry matter } \\
(\%)\end{array}$ & $\begin{array}{l}\text { Starch content } \\
(\%)\end{array}$ & $\begin{array}{l}\text { Ethanol capacity } \\
(\mathrm{ml} / \mathrm{g})\end{array}$ \\
\hline 1 & Ahotonon & 42.33 & $1.15 \pm 0.12$ & 0.090 \\
\hline 2 & Akparokofo rouge & 34.26 & $4.17 \pm 0.5$ & 0.088 \\
\hline 3 & Analo Bara & 26.44 & $4.52 \pm 0.51$ & 0.164 \\
\hline 4 & Analo bièsso & 27.36 & $0.14 \pm 0.01$ & 0.101 \\
\hline 5 & Atinwé & 44.45 & $3.06 \pm 0.03$ & 0.105 \\
\hline 6 & Atinwi & 39 & $5.01 \pm 0.51$ & 0.100 \\
\hline 7 & Avion de terre & 38.5 & $2.87 \pm 0.42$ & 0.102 \\
\hline 8 & Awoubièlou & 44.82 & $1.54 \pm 0.16$ & 0.088 \\
\hline 9 & Babarobert & 42.4 & $0.61 \pm 0.05$ & 0.095 \\
\hline 10 & BEN & 28.34 & $2.56 \pm 0.43$ & 0.090 \\
\hline 11 & Blanwidji & 23.8 & $6.91 \pm 0.5$ & 0.108 \\
\hline 12 & Briguédé(Pourou) & 22.24 & $10.28 \pm 1.1$ & 0.090 \\
\hline 13 & Carder Blanc & 31.87 & $2.14 \pm 0.32$ & 0.075 \\
\hline 14 & Danandanan & 44.76 & $0.23 \pm 0.03$ & 0.044 \\
\hline 15 & Dokouin & 37.8 & $1.45 \pm 0.15$ & 0.068 \\
\hline 16 & Fofovi & 47.25 & $2.36 \pm 0.2$ & 0.081 \\
\hline 17 & Goro & 22.2 & $6.30 \pm 0.06$ & 0.151 \\
\hline 18 & Houlamin & 33.66 & $2.80 \pm 0.50$ & 0.095 \\
\hline 19 & Israel & 14.37 & $2.02 \pm 0.02$ & 0.063 \\
\hline 20 & Kominan & 33.36 & $1.30 \pm 0.07$ & 0.130 \\
\hline 21 & Koukpabiekpo & 35.16 & $2.16 \pm 0.03$ & 0.108 \\
\hline 22 & Kpassa & 43.81 & $2.38 \pm 0.24$ & 0.110 \\
\hline 23 & Krokotoya & 45.16 & $0.54 \pm 0.04$ & 0.070 \\
\hline 24 & Lèlibô & 43.2 & $5.76 \pm 0.80$ & 0.086 \\
\hline 25 & Loki pétiole rouge & 45.06 & $1.62 \pm 0.17$ & 0.162 \\
\hline 26 & Monlèkangan & 43.69 & $5.03 \pm 0.51$ & 0.068 \\
\hline 27 & Offêguê & 11.26 & $0.99 \pm 0.02$ & 0.077 \\
\hline 28 & Okoognibo & 35.86 & $6.46 \pm 0.58$ & 0.121 \\
\hline 29 & Oligbessè & 17.26 & $2.56 \pm 0.40$ & 0.125 \\
\hline 30 & Sokounon & 45.36 & $4.99 \pm 0.59$ & 0.120 \\
\hline 31 & Sowé & 50.8 & $4.67 \pm 0.50$ & 0.108 \\
\hline 32 & Tatawili & 40.01 & $6.38 \pm 0.65$ & 0.090 \\
\hline 33 & TMS & 42.36 & $11.14 \pm 1.86$ & 0.274 \\
\hline 34 & Yêkè & 45.25 & $6.12 \pm 0.62$ & 0.076 \\
\hline \multicolumn{2}{|c|}{ Average mean } & 35.98 & 3.59 & 0.10 \\
\hline \multicolumn{2}{|c|}{ Minimum } & 11.26 & 0.14 & 0.04 \\
\hline \multicolumn{2}{|c|}{ Maximum } & 50.8 & 11.14 & 0.27 \\
\hline \multicolumn{2}{|c|}{ Standard deviation } & 10.083 & 2.66 & 0.04 \\
\hline \multicolumn{2}{|c|}{ Coefficient of variation (\%) } & 28.01 & 74.01 & 38.60 \\
\hline
\end{tabular}


The starch content of the cultivars analyzed varies from $0.14 \mathrm{mg} / \mathrm{g}$ to $11.14 \mathrm{mg} / \mathrm{g}$ with an average of $3.56 \mathrm{mg} / \mathrm{g}$ (Table 2). As reported by Essuma et al. (2012), Robooni et al. (2012), the variability observed may be due to the genotypes and to the environment. The lowest value was found with the cultivar Analo-Biesso while cultivar TMS presented the highest value. TMS widely preferred by farmers for it starch richness is an improved cassava cultivar developed by IITA and popularized by Benin National Agricultural Research Institute (INRAB). Out of the 34 cultivars analyzed, 14 showed value higher than the average recorded. Assessment of the starch content is important to direct NGOs, processors' associations and starch production industries established in Benin in the choice of cassava cultivar to be used for better productivity and profit margin.

The alcohol production capacity varies considerably with the type of the cassava used. The highest value $(0.274$ $\mathrm{ml} / \mathrm{g}$ ) was found with TMS, while the lowest value $(0.044 \mathrm{ml} / \mathrm{g})$ was recorded with cultivar Danandanan. The average value was $0.103 \mathrm{ml} / \mathrm{g}$ (Table 2). Therefore, one ton of cassava root could generate in average 103 liters of alcohol which is lower than the value of about 280 liters of pure ethanol at $96 \%$ indicated by FAO (2013) on the basis of one ton of $30 \%$ (wet weight basis) starch content cultivar. Analysis of the correlation matrix between variables (Table 3) showed high and positive correlation value ( $r=0.48)$ between starch content and the alcohol production capacity. Most of the high starch content cultivars showed average to high value of ethanol production capacity (Table 2). This is understandable since ethanol is produced by the starch fermented through yeast metabolisms. Surprisingly, the moderate sweet cassava cultivar Analo-bièsso (Agre et al., 2015) which presented the lowest value of the starch content showed high value $(0.14 \pm 0.01 \mathrm{ml} / \mathrm{g})$ for alcohol production capacity. Guindo (2008) reported that bitter cassava cultivars yield less alcohol than sweet cultivars. This is contrary to the report of Hongbétè et al. (2011) according to which, bitter cultivars have higher soluble sugar contents than the sweet ones and this normally lead to high power of fermentation. It is therefore likely that simple sensorial analysis classifying cultivars into sweet or bitter cannot help strongly predicting the alcohol production capacity of a given cultivar.

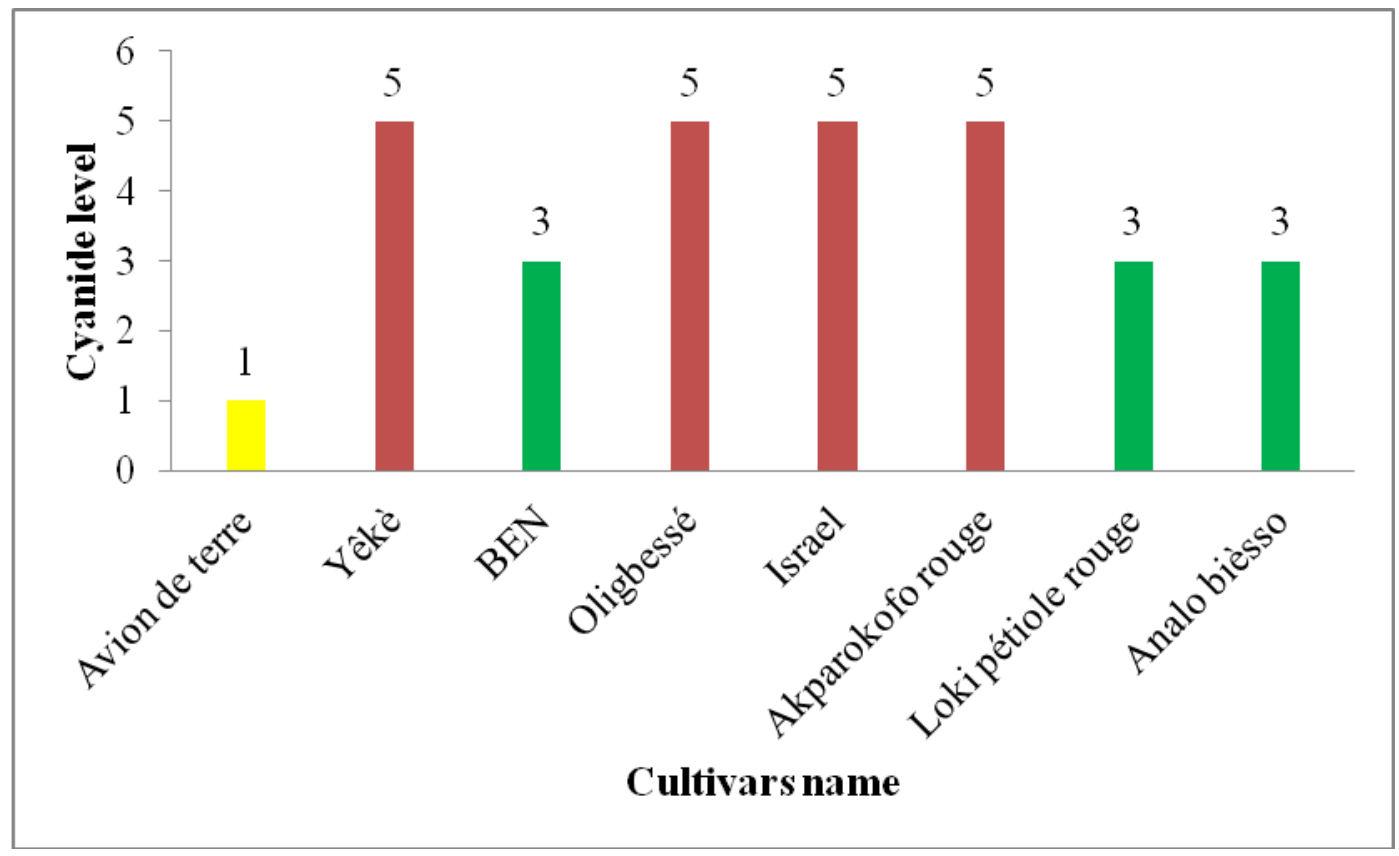

Legend: $1=$ Low level of presence; 3 = Average level of presence; $5=$ High level of presence

Fig. 1: Level of presence of cyanide compounds in the eight elite but toxic cassava cultivars analyzed.

Among the 34 elite cassava cultivars analyzed, 8 were known to be toxic (Agre et al., 2015) and assessed for their qualitative content in cyanide compounds. The results showed as expected that the cyanide level varies according to the cultivars (Fig. 1). Four cultivars presented high level of cyanide while three indicated average cyanide level and one has low cyanide level (Fig. 1). As reported by Sanoussi et al. (2015), high 
correlation was found between farmers' evaluation and the results of the chemical analysis hence indicating the importance of taking into account the farmers' knowledge in varietal documentation or evaluation. Some bitter cultivars often contain more soluble sugars than the sweet cultivars (Padonou et al., 2005) and may be scored by consumers as not bitter (Houngbété et al., 2011). Similarly cultivar with low cyanide and sugar content may be scored as the most bitter (Hongbété et al., 2011; Sanoussi et al., 2015). These observations are in agreement with the recommendation of Hongbété et al. (2011) which is that sensorial analysis of bitterness as indirect method for predicting cyanide-rich cultivars should be avoided. As reported by Mehouenou et al.
(2016), the cassava cultivars analyzed in this study based on their perceived bitterness (and especially those with high and average level of cyanide) may contain after quantitative analysis less than $50 \mathrm{mg} \mathrm{HCN}$ per $\mathrm{kg}$ of freshly grated cassava and then can be considered innocuous (Maziya-Dixon et al., 2005) for raw consumption of the roots. Therefore, quantitative cyanide content analysis is recommended for both bitter and sweet cultivars to certify and not their innocuousness. However, in many localities, and to avoid food poisoning, cassava cultivars rich in cyanide acid are used by farmers' only after many processing steps that lead to the elimination of these cyanide compounds (Cardozo et al., 2005; Hongbété et al., 2009).

Table 3. Correlation between the variables and the main factors.

\begin{tabular}{lllll}
\hline Variables & Fact $\mathbf{1}$ & Fact 2 & Fact 3 & Fact 4 \\
\hline Gari & -0.38 & -0.55 & $0.75^{* *}$ & 0.00 \\
Tapioca & -0.06 & $0.89 * *$ & 0.44 & -0.06 \\
Cassava chips & $0.99^{* *}$ & -0.10 & 0.04 & -0.07 \\
Attièkè & $0.95^{* *}$ & 0.16 & 0.18 & 0.20 \\
Cassava flour & $0.99^{* *}$ & -0.10 & 0.04 & -0.07 \\
Alcohol production capacity & $0.99^{* *}$ & -0.10 & 0.04 & -0.07 \\
\hline
\end{tabular}

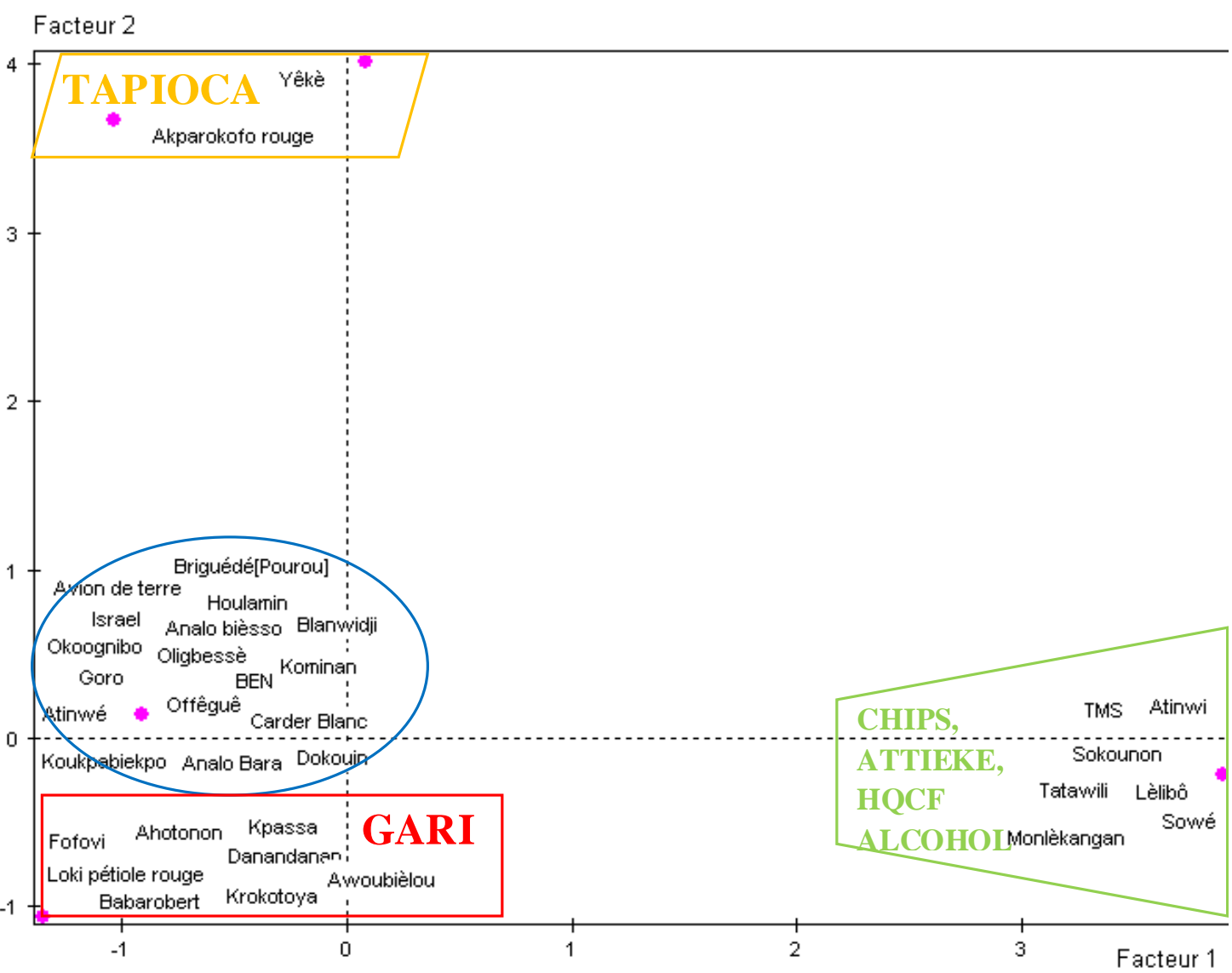

Fig. 2: Grouping of the elite cassava cultivars based on their physicochemical properties and their aptitude for being processed into different foods. 


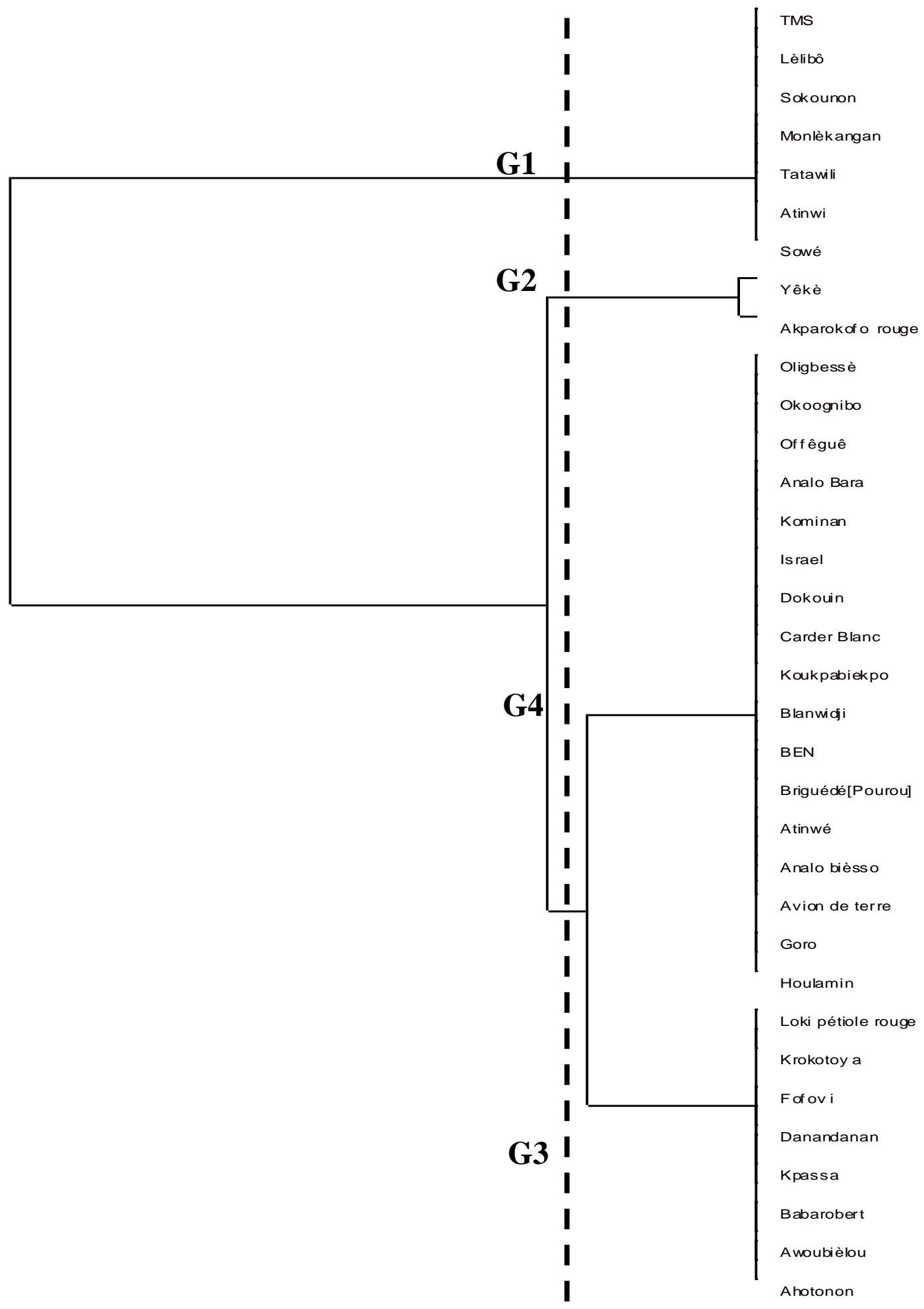

Fig. 3: Dendrogram showing the grouping of the elite cassava cultivars of central Benin. 


\section{Classification of the elite cultivars using ACP and cluster analysis}

The first two factors of the Principal component analysis (PCA) explained $75.65 \%$ of the total variation. Cassava chips, attièkè, high quality cassava flour and alcohol production capacity were positively correlated with the first factor of the PCA while only aptitude for tapioca production is positively correlated to the second factor (Table 3). The projection of the elite's cassava cultivars on factorial axis (Factor 1 and 2) led to four groups (Fig. 2 and Fig. 3):

- The first group is composed of 7 cultivars (Atinwi, Sokounon, Lélibo, Sowé, Molékanga, TMS and Tatawilli) good for cassava chips, attièkè, high quality cassava flour and have also high ethanol production capacity.

- The second group is made of two cultivars (Akparofoko and Yêkè) that are good for tapioca

- The third group assembled 8 cassava cultivars (Ahotonon, Awoulbiélou, Babarobert, Danandanan, Kpassa, Krokotoya, Fofovi, and Loki) that could be easily used to make a good gari.

- The last group is made of seventeen (17) elite cultivars of cassava that can be used for any technology but without reaching the goal of the best quality with the higher yield of production and best profit margin.

The 17 cultivars of the group 1,2 and 3 could be considered as super elite cassava. The dendrogramme constructed to confirm the result obtained through PCA, also yielded the 4 main groups previously obtained.

\section{Conclusion}

This study helped to identify among the elite cassava cultivars of central Benin those that are suitable for the most popular local cassava based foods. For better development of the cassava value chain in Benin the knowledge here generated should be capitalized by food technologists and cassava breeders.

Seventeen (17) cassava cultivars have been considered as super elite with interesting aptitude for producing gari, tapioca, HQCF, cassava chips or alcohol with good profit margin. For future study, the rheological characteristics of the starch of each super elite cassava cultivars should be determined and economic study should be conducted to assess the profit margin when using appropriate cultivar.

\section{Conflict of interest statement}

Authors declare that they have no conflict of interest.

\section{Acknowledgement}

This study was sponsored by UEMOA through PAES project. We thank anonymous reviewers for their suggestions and constructive criticisms. We express our gratitude to the cassava farmers of central Benin for providing useful information during ethnobotanical survey.

\section{References}

Agre, A.P., Dansi, A., Rabbi, I.Y., Battachargee, R., Dansi, M., Melaku, G., Augusto, B., Sanni, A., Akoègninou, A., Akpagana, K., 2015a. Agromorphological characterization of elite cassava (Manihot esculenta Crantz) cultivars collected in Benin. Int. J. Curr. Res. Biosci. Plant Biol. 2(2), 1-14.

Agre, A.P., Bhattacharjee, R., Dansi, A., Becerra LopezLavalle, L. A., Dansi, M., Sanni, A., 2015b. Assessment of cassava (Manihot esculenta Crantz) diversity, loss of landraces and farmers preference criteria in southern Benin using farmers' participatory approach. Genet. Resour. Crop Evol. Online first. DOI 10.1007/s10722015-0352-1

AOAC, 2000. Official Method of Analysis of the Association of Official Analytical Chemists. $16^{\text {th }}$ Edn. AOAC, Arlington, Va, USA.

Chavent,M., Kuentz, V., Saracco, J., 2007. Analyse en Facteurs: présentation et comparaison des logiciels SAS, SPAD et SPSS. Revue Modulad, 37, 1-30.

Cardoso, A.P., Mirione, E., Ernesto, M., 2005. Processing of cassava roots to remove cyanogens. J. Food Comp. Anal. 18(5), 451-460.

Ebuehi, O., Babalola, O., Ahmed, Z., 2006. Phytochemical, nutritive and anti-nutritive composition of cassava (Manihot esculenta) tubers and leaves. Nigerian Food J. 23(1), 40-46.

Esuma, W., Patrick, R., Anthony, P., Robert, K., Bramwel, W., 2012. Genetic diversity of provitamin A cassava in Uganda. J. Plant Studies. 1(1), 60-70.

Falade, K.O., Akingbala, J.O., 2008. Improved nutrition and national development through the utilization of cassava in baked foods. International Union of Food Science \& Technology. pp.1-12.

FAO, 2013. Base de données statistiques FAOSTAT (http://faostat.fao.org).

Hongbété, F., Mestres, C., Akissoé, N., Pons, B., Hounhouigan, D. J., Cornet, D., Nago, C.M., 2011. Effects of cultivar and harvesting conditions (age, season) on the texture and taste of boiled cassava roots. Food Chem. 126, 127-133. 
Hongbete, F., Mestres, C., Akisso'e, N., Nago, C.M., 2009. Effect of processing conditions on cyanide content and colour of cassava flours from West Africa. Afr. J. Food Sci. 3(1), 1-6.

Maziya-Dixon, B., Adebowale, A.A., Onabanjo, O.O., Dixon, G.G., 2005. Effect of variety and drying methods on physicochemical properties of high quality cassava flour from yellow cassava roots. Afr. Crop Sci. 7, 635-641.

Mehouenou, F.M., Dassou, A., Sanoussi, F., Dansi, A., Adjatin, A., Ahissou, H., 2016. Physicochemical characterization of cassava elite cultivars (Manihot esculenta) of southern Benin. Int. J. Adv. Res. Biol. Sci. 3(3), 190-199.

Nago, C.M., Hounhouigan, D.J., Akissoe, N., Zanou, E., Mestres, C., 1998. Characterization of the Beninese traditional ogi, a fermented maize gruel: physico-chemical and microbiological aspects. Int. J. Food Sci. Technol. 33(3), 307-315.

Onubuogu, G.C., Esiobu, N.S., Nwosu, C.S., Okereke, C.N., 2014. Resource use efficiency of smallholder cassava farmers in Owerri Agricultural zone, Imo State, Nigeria. Scholarly J. Agric. Sci. 4(6), 306-318.

Padonou, W., Mestres, C., Nago, M.C., 2005. The quality of boiled cassava roots: instrumental characterization and relationship with physicochemical properties and sensorial properties. Food Chem. 89(2), 261-270.

Parkes, E.Y., Fregene, M., Dixon, A., Boakye-Peprah, B., Labuschagne, M.T., 2013. Combining ability of cassava genotypes for cassava mosaic disease and cassavabacterial blight, yield and its related components in two ecological zones in Ghana. Euphytica. 194, 13-24.

Rahmi, B., Yanti, Y., Mizumachi, S., Achmadi, J., Kawamoto, Y., Purnomoadi, A., 2008. Effects of drying and ensiling methods on cyanides contents and chemical components of cassava roots and stems. J. Indonesian Trop. Anim. Agric. 33(4), 247-254.

Robooni, T., Melis, R., Shanahan, P., Kawuki, R., 2012. Farmers' perceptions on early storage root bulking in cassava (Manihot esculenta Crantz) in East and Central Uganda and their implication for cassava breeding. World J. Agric. Sci. 8(4), 403-408.

Sanoussi, A. F., Dansi, A., Ahissou, H., Adebowale, A., Sanni, L. O., Orobiyi, A., Dansi, M., Azokpota, P., Sanni, A., 2016. Chemical composition of ten elite sweet potato (Ipomoea batatas (L.) Lam.) landraces of Benin. Afr. J. Biotechnol (In press).

Sanoussi, A. F., Loko, L. Y., Ahissou, H., Adjahi, A. K., Orobiyi, A., Agré, A. P., Azokpota, P., Dansi, A., Sanni, A., 2015. Diversity, physicochemical and technological characterization of elite cassava (Manihot esculenta Crantz) cultivars of Bantè, a district of central Benin. Scient. World J. 2015(2015), Article ID 674201, 8 pages. http://dx.doi.org/10.1155/2015/674201.

Singh, J., Kaur, L., Mccarthy, O. J., 2007. Factors influencing the physico-chemical, morphological, thermal and rheological properties of some chemically modified starches for food application-A review. Food Hydrocoll. $21,1-22$.

\section{How to cite this article:}

Gbessovi, D. R., Agre, P., Sanoussi, A. F., Dassou, A., Dansi*, A., Adjatin, A., Dansi, M., Ahissou, H., 2016. Physicochemical characteristics and suitability for selected local foods of the elite cassava (Manihot esculenta Crantz) cultivars of central Benin. Int. J. Curr. Res. Biosci. Plant Biol. 3(3), 39-47. doi: http://dx.doi.org/10.20546/ijcrbp.2016.303.008 